\title{
A COMPARATIVE STUDY ON SINGLE AND DOUBLE JOINTED CU-AL BIMETALLIC STRIPS USING FRICTION STIR SPOT WELDING PROCESS
}

\author{
* Karunakaran D and Venkatachalapathy VSK
}

Department of Mechanical Engineering, Sri Manakula Vinayagar Engineering College, Madagadipet, Puducherry-605 107, India https://doi.org/10.37255/jme.v15i3pp66-71

\begin{abstract}
Welding is one of the best and quick process to join metals. In modern times, we concern more about environmental hazards due to hazardous gases liberated during conventional welding processes. Fiction Stir welding is a simple process in which a solid metal joint is produced by the heat of friction. In a similar technique, we can make spot welds of similar or dissimilar metallic joints by using Friction Stir Spot Welding. Since there is an absence of any liberation of poisonous gases, this method is safe to the environment and user. In this study, we made a dissimilar lap joint of Copper and Aluminium strips using an H13 steel tool. The pin profile of the tool is based on the thickness of the plate/weld. Weld based process parameters such as tool rotational speed, Dwell time and plunge depth. A lap joint with a desirable overlapping length between friction weld spots is compared and analyzed for mechanical bonding strength for both single and double joints. The results show a considerable increase in tensile strength for double-jointed specimen compared to a single-joint.
\end{abstract}

Keywords: Friction stir spot weld; dissimilar weld joint; Bonding strength; green welding process

\section{Introduction}

Friction stir spot welding (FSSW) has been developed based on the basic principles of linear FSW, without lateral movement of the tool. The FSSW process is illustrated in Fig.1[1]. The purpose is to spot weld two or more overlapping sheets by plunging the rotating tool at a specific rate until the shoulder makes contact with the upper sheet, while a stationary anvil provides backing support for the axial loads. In order to reach the desired temperature required for plastic flow, a short dwell phase is often useful, especially for high melting point materials. This dwell phase also increases the volume of deformed material and promotes material flow and mixing between the upper and lower sheet material [2]. The material around the tool is softened and plastically deformed to high strains during the plunge and dwell stages, and the tool movement in the vertical direction facilitates the flow of plasticized material in both circumferential and axial directions, which also helps to disrupt the oxide layer at the joint interface. Once the weld is formed, the tool is then retracted rapidly either once the target plunge depth is reached, or after a dwell period.

The combination of forging pressure, heating and material flow of the plasticized material produces an annular, solid-state metallurgical bond, which comprises

*Corresponding Author - E- mail: karunakaran@smvec.ac.in a fine-grained microstructure with high-angle grain boundaries adjacent to the rotating tool. Similar to FSW, joining using FSSW also takes place by extrusion and forging of the material at high strain rates [3]. The complex interactions between the simultaneous thermomechanical processes which determine the heat and mass transfer, affect the heating and cooling rates, plastic deformation and flow, leading to recrystallization phenomena.

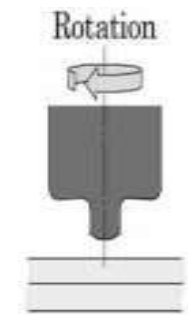

(a)

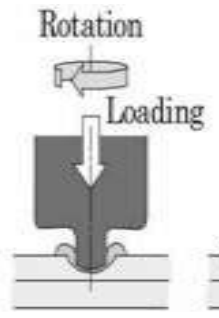

(b)

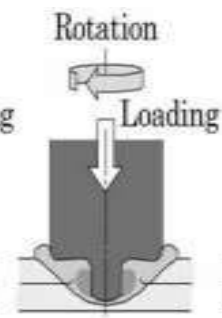

(c)

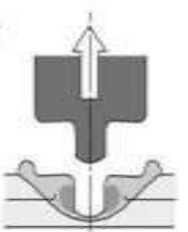

(d)
Fig. 1 Illustration of the FSSW process

The FSSW process is much more complicated in the sense that the actual welding time itself is shorter, but the process dynamics all focus on the transient stages of the tool plunge, material mixing and tool retraction. There is no tool advancing or retreating side, and the FSSW process can be considered to be 
axisymmetric due to the absence of the traverse movement.

\subsection{Heat input during friction stir spot welding}

During FSW, the tool moves over the base metal, stirring, deforming and mixing it. The parent material, the anvil and the tool increase in temperature due to the influence of the tool on the parent material. This variation in temperature is a clear indication of the heat generation caused by frictional contact that takes place during the welding process [4]. In FSSW welding, the heat input is calculated by integrating the torque curve, and then using the Equation 1 given below:

$$
U=\frac{2 \pi}{60} \omega \int_{t_{0}}^{t_{s}} T d t
$$

Where

$\omega$ : Tool rotation speed in $\mathrm{rpm}$,

T: Torque in N-m

$\mathrm{U}$ : Heat input in Joules

$t_{0}$ and $t_{s}$ : Tool contact and withdrawal time in seconds.

\section{Literature Survey}

Metallurgical Analysis of $\mathrm{Al} / \mathrm{Cu}$ Friction Stir Spot Welding by Heideman [5] notified that when the rotational speed was increased from $1000 \mathrm{rpm}$ to 2000 $\mathrm{rpm}$, the weld strength was increased to $150 \%$ of the average weld strength. Also, when the pin length was increased from $1.83 \mathrm{~mm}$ to $2.60 \mathrm{~mm}$ the weld strength was increased $70 \%$ of the produced average weld strength are produce at the rotational speed of $2000 \mathrm{rpm}$ for the analysis of the high welding strength of the rotational speed.

Mukuna et al. [6] found that the copper ring length increased with the increase of the shoulder plunge depth, except for the spot welds produced at $1200 \mathrm{rpm}$, using a flat pin and shoulder, where a decrease was seen. It demonstrates that the welds produced at high rotational speed display either a decrease or a slight increase. It has been reported that the copper ring caused interlocking between the two plates and help the plates stick to each other through the tensile test, and this will result in reaching a high strength before failure. The shoulder plunge depth increased, the failure load increased, except for the weld produced at $800 \mathrm{rpm}$ when using a conical pin and a concave shoulder. By increasing shoulder plunge depth, high strength welds were obtained.

Raheem et al. [7] stated that the heat generated equal to $50^{\circ} \mathrm{Celsius}$ in case of automatic process and $210^{\circ}$ Celsius in case of the manual process. The dwell time to complete the welding process in case of automatic process reduced to be $14 \%$ of the time that consume in the case of manual welding process because the applied is twice the time of manual applied load.

From the literature survey, it is notified that there is a need for the comparative study of single and double-jointed strips to know whether any significant change in strength and stability while varying tool rotation speed.

\section{Experimental Details}

\subsection{Design and Fabrication}

Tool design features such as geometry or tool material, and process parameters including rotational speed, plunge rate, plunge depth and dwell time are critical to the success of the FSSW technology, since these factors significantly affect heat generation, material flow, torque, axial force, weld integrity and tool degradation mechanisms [8]. Low heat generation and insufficient material flow could result in defects such as voids, lack of bonding, incomplete refill, or inadequate bonded areas. However, with higher heat input, grain growth, or excessive softening of the surrounding HAZ occurs as a result of precipitate dissolution. In order to explore the optimum tool design and process [9] parameters, it is vital to gain a better understanding of mechanisms influencing these factors.

\subsection{Tool}

A unique tool with $\mathrm{H} 13$ was used as given in Fig. 2. The dimension of the tool is shoulder diameter $18 \mathrm{~mm}$, pin diameter $5.5 \mathrm{~mm}$, major diameter $20 \mathrm{~mm}$, pin length of $5 \mathrm{~mm}$. Milling machine type HMT Fn3V with a spindle rotation speed between 25.5 to $1800 \mathrm{rpm}$ with some modification in the vice to make the lap joint [10].

\subsection{Materials Used}

Copper (C11000) flat plat and Aluminium (AA1100) flat plat are been used for joining. Two different size of plates of $25 \mathrm{~mm} * 100 \mathrm{~mm}$ for single spot weld and $25 \mathrm{~mm} * 120 \mathrm{~mm}$ for double spot weld [11]. The flat plate of $\mathrm{Cu}$ alloy and $\mathrm{Al}$ alloy is of $3 \mathrm{~mm}$ thickness each. Before welding, the specimens should be cut with shear off machine and surface grounded to remove unwanted layers of oxides and formed scales. The properties of base alloys are follows $\mathrm{Cu}(90.73 \% \mathrm{Cu}$, 9.15\%Zn, $0.01 \% \mathrm{Ti}, 0.02 \% \mathrm{k})$ and $\mathrm{Al}(0.25 \% \mathrm{Zn}$, $0.15 \& \mathrm{Ti}, 0.7 \% \mathrm{Fe}, 0.15 \% \mathrm{Cu}, 0.33 \% \mathrm{~mm}, 0.53 \% \mathrm{Si}$, $0.69 \% \mathrm{Mg}, 95.8 \% \mathrm{Al}$ ) [12]. The material properties of Copper and Aluminium are shown in Table 1. 

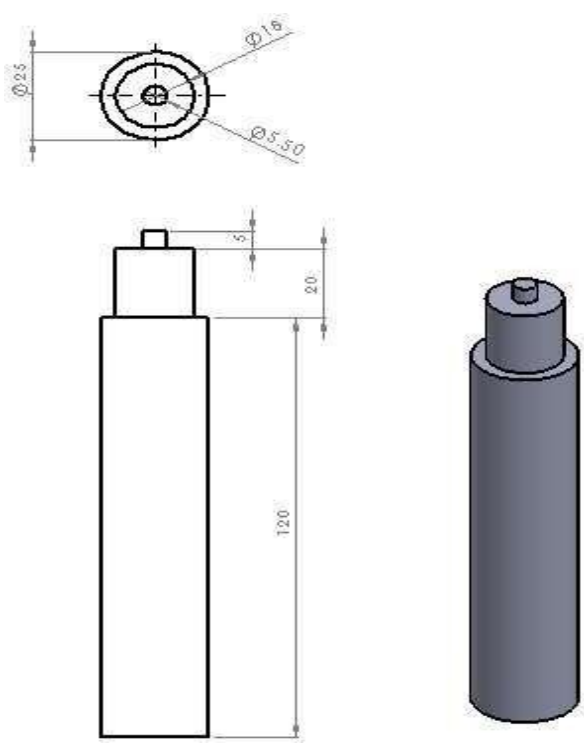

Fig. 2 Tool used to carry out the spot weld

Table 1 Mechanical Properties of Copper and Aluminium

\begin{tabular}{ccccc}
\hline $\begin{array}{c}\text { Meta } \\
\text { I }\end{array}$ & $\begin{array}{c}\text { Hardness } \\
\text { HV }\end{array}$ & $\begin{array}{c}\text { Tensile } \\
\text { Strength } \\
\text { Mpa }\end{array}$ & $\begin{array}{c}\text { Yield } \\
\text { strength } \\
\text { MPa }\end{array}$ & $\begin{array}{c}\text { Elonga } \\
\text { tion } \\
\%\end{array}$ \\
\hline $\mathrm{Cu}$ & $50-65$ & $90-135$ & $34-150$ & $9.9-25$ \\
$\mathrm{Al}$ & $55-115$ & $210-310$ & - & $7-40$ \\
\hline
\end{tabular}

\subsection{Design of Modified Fixture}

For proper support and to tackle dynamic forces, it is essential to provide firm support to the meta pieces. A unique fixture, as shown in Fig. 3 has a vicelike arrangement firmly fixed with long bolt and nut and tightened to avoid lateral movement during high rotation of the tool. Since the process uses friction to produce joint, to give stability and withstand a high amount of vibration, a unique fixture is required [13].

\subsection{FSSW PROCESS PARAMETERS:}

Dwell Time: The period of time after the rotating tool has been plunged into the work, and for which it remains stationary, generating frictional heat and plasticizing the materials, before commencing the traverse along the joint (seconds).

Axial Load: The Load with which the tool is pressed towards the specimen.

Overlapping Length: This amount of overlapping between two bars is called "lap length". Lapping is usually done where minimum bending stress is encountered. Overlapping length for the single spot is $25 \mathrm{~mm}$ whereas in the double spot is $45 \mathrm{~mm}$.

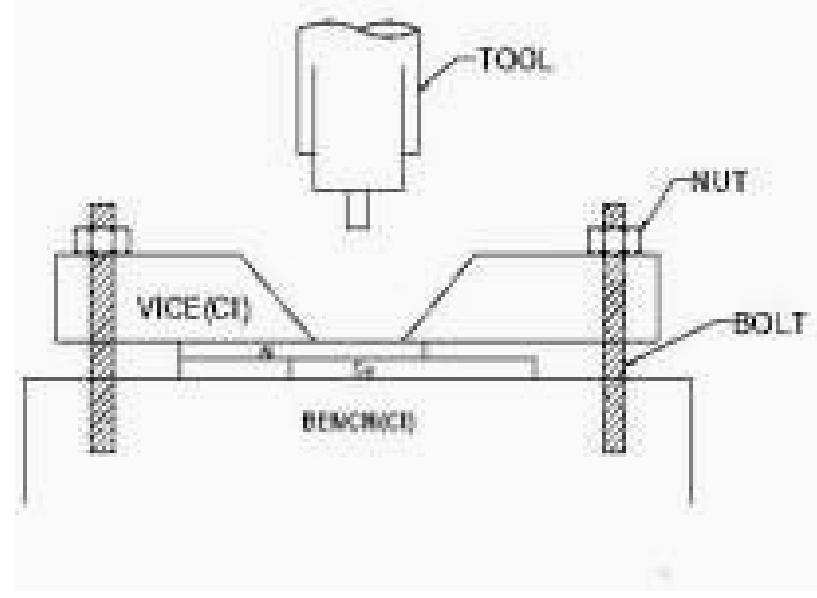

Fig. 3 Schematic diagram of the modified fixture.

Speed (rpm): It is defined as the number of revolutions at which the spindle rotates per minute. 900, 1120 and $1400 \mathrm{rpm}$ speeds are used for both single and double joints.

Single spot: There will be only one weld spot with the overlapping length of $25 \mathrm{~mm}$.

Double spot: There will be two spots with an overlapping length of $45 \mathrm{~mm}$.

The single and double spot welded pieases are illustrated in Figs. 4 and 5 respectively.

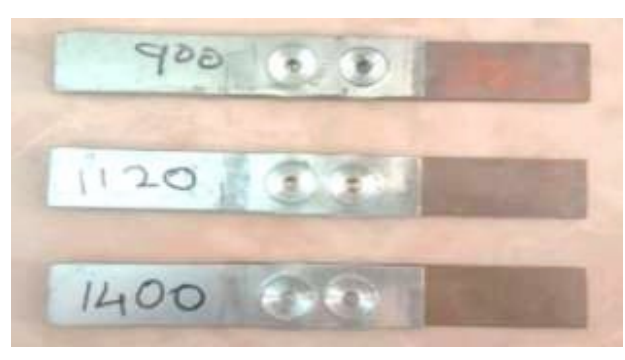

Fig. 4 Single spot-welded pieces at the speeds of 900 , 1120 and $1400 \mathrm{rpm}$

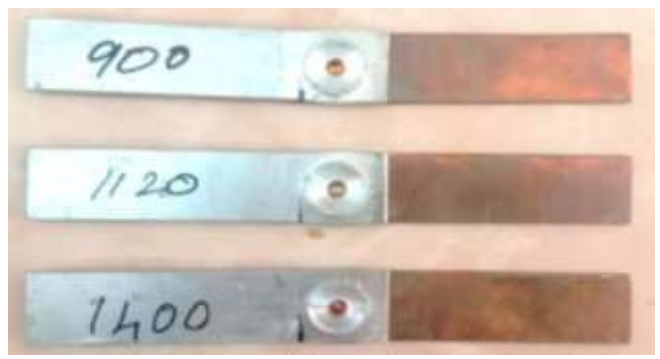

Fig. 5 Double spot-welded pieces at the speeds of 900, 1120 and $1400 \mathrm{rpm}$ 


\section{Results and Discussion}

From the SEM images and the result of transverse tensile strength, analysis results are made and discussed as follows. For easy identification and good understanding, the samples with different speeds are named and identified as below:

$$
\begin{aligned}
& \text { A-900 rpm Single Spot } \\
& \text { B-900 rpm Double Spot } \\
& \text { C-1120 rpm Single Spot } \\
& \text { D-1120 rpm Double Spot } \\
& \text { E-1400 rpm Single Spot } \\
& \text { F-1400 rpm Double Spot }
\end{aligned}
$$

\subsection{Comparison of (A) And (E)}

While comparing the maximum and minimum speed of Single spot weld, we see the images of SEM analysis of $900 \mathrm{rpm}$ single spot (A) and $1400 \mathrm{rpm}$ single spot (E) are compared below.

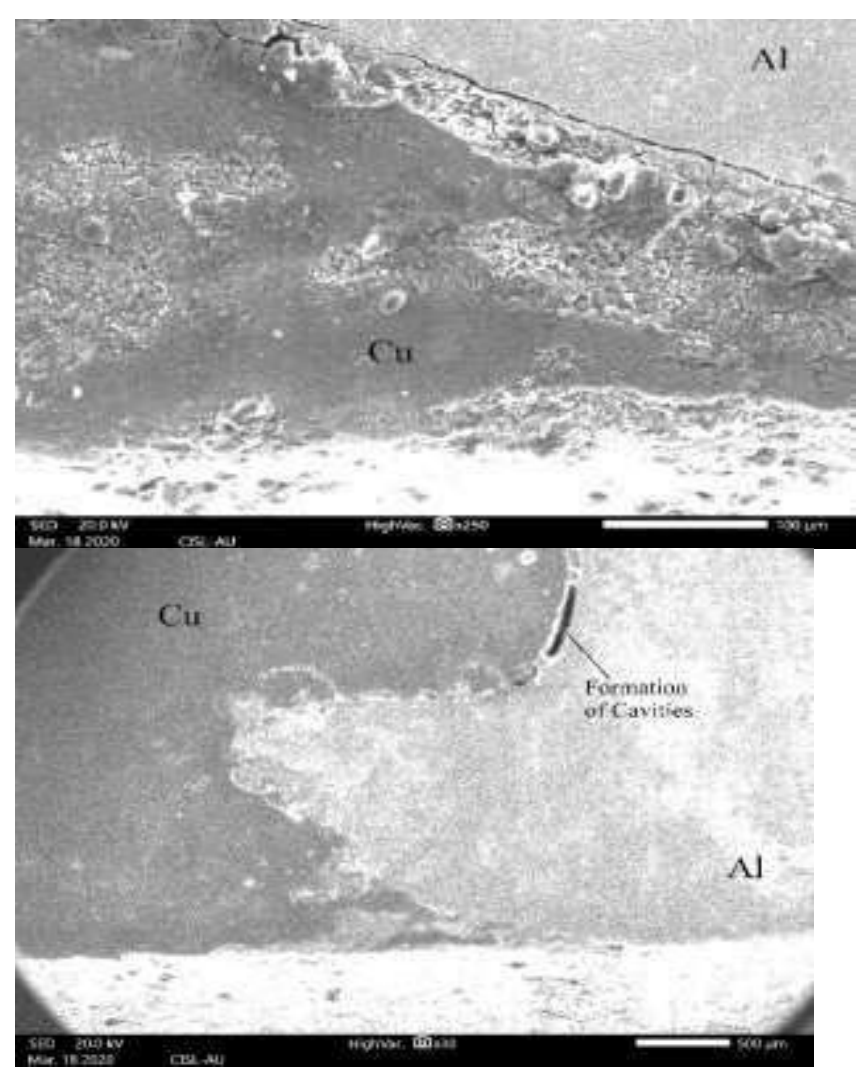

Fig 6. A (900 rpm single)

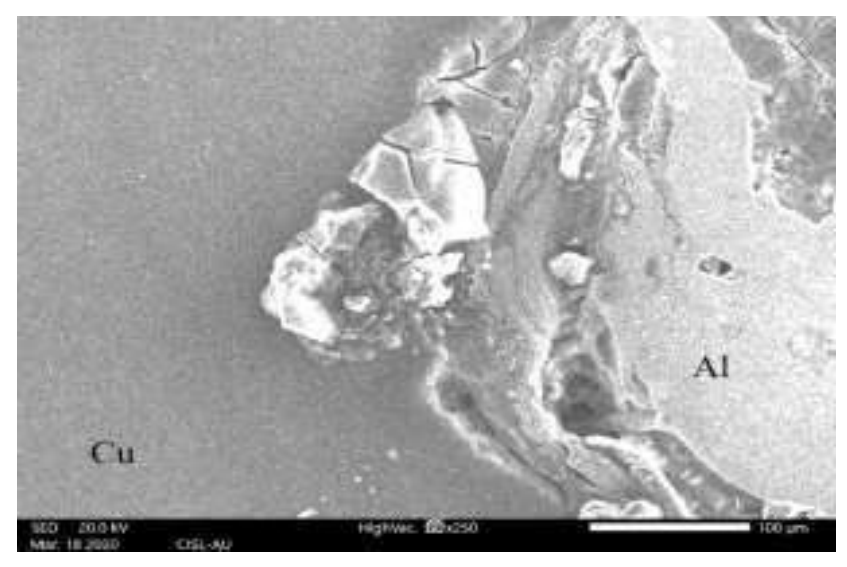

Fig 7. E (1400 rpm Single)

The formation of cavities and unsatisfied bonding is seen in Fig. 6 than Fig. 7. The transverse tensile strength result of (A) and (E) is $29.20 \mathrm{~N} / \mathrm{mm}^{2}$ and $38.27 \mathrm{~N} / \mathrm{mm}^{2}$ respectively. From this comparison of tensile strength report and SEM images, it is found that more diffusion and good bond strength is occurred in (E) than (A) due to increasing the speed of tool rotation. Hence, it is studied that tensile strength increases in increasing tool rotation.

\subsection{Comparison of $(A)$ and $(B)$}

While comparing Single and Double welds at the minimum speed of $900 \mathrm{rpm}$, we observe that the image of SEM of $900 \mathrm{rpm}$ single spot (A) and $900 \mathrm{rpm}$ double spot (B) weld is compared below:

From these images, Fig. 7 has more cavities, oxide layers are present at the interface and microcracks are formed near the nugget or hook region than Fig. 8. The tensile report also says that the tensile strength of (A) is $29.20 \mathrm{~N} / \mathrm{mm}^{2}$ and (B) is $78.40 \mathrm{~N} / \mathrm{mm}^{2}$, respectively.

From this comparison of tensile strength report and SEM images, it is seen that the cavities, cracks and weld defects are less in (B) than (A) which shows that (B) is with good strength and gives satisfactory weld.

Hence, it is observed that strength and efficiency increase with the increase in the number of welds. 
Journal of Manufacturing Engineering, September 2020, Vol. 15, Issue. 3, pp 066-071

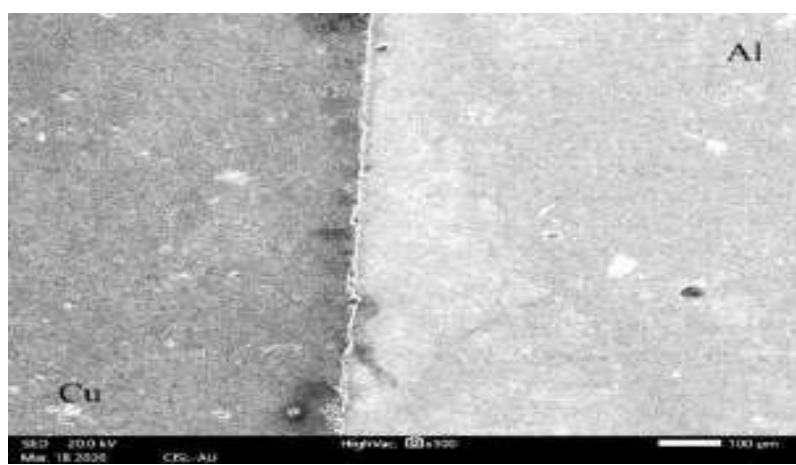

Fig 8. B (900 rpm double)

\subsection{Comparison of $(B)$ and $(F)$}

The SEM images of $900 \mathrm{rpm}$ double spot (B) and $1400 \mathrm{rpm}$ double spot $(\mathrm{F})$ is seen as follows:

From the Fig. 9 and Fig. 10, it is seen that better diffusion took place and mechanical interlocking is more in Fig (F) due to increase in speed and due to the increase in the number of welds. On comparing the tensile strength of (B) and (F), (B) has $78.40 \mathrm{~N} / \mathrm{mm}^{2}$ and (F) has $80.80 \mathrm{~N} / \mathrm{mm}^{2}$, respectively. From these results of tensile strength report and SEM images, it is found that (F) has better mechanical interlocking, good strength than (B). Hence, among all-welded samples (F) has a better diffusion process, proper bonding and high tensile strength due to an increase in the tool rotation speed and a greater number of welds.

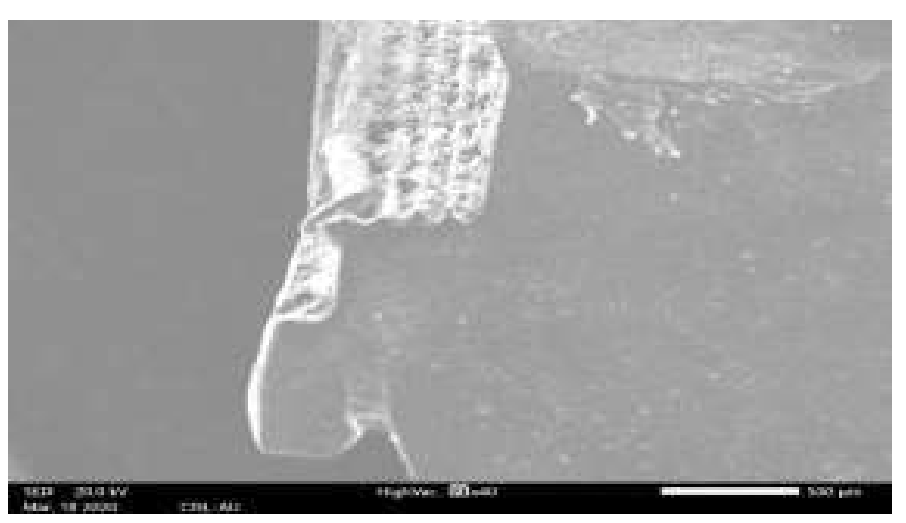

Fig 9. B (900 rpm Double)

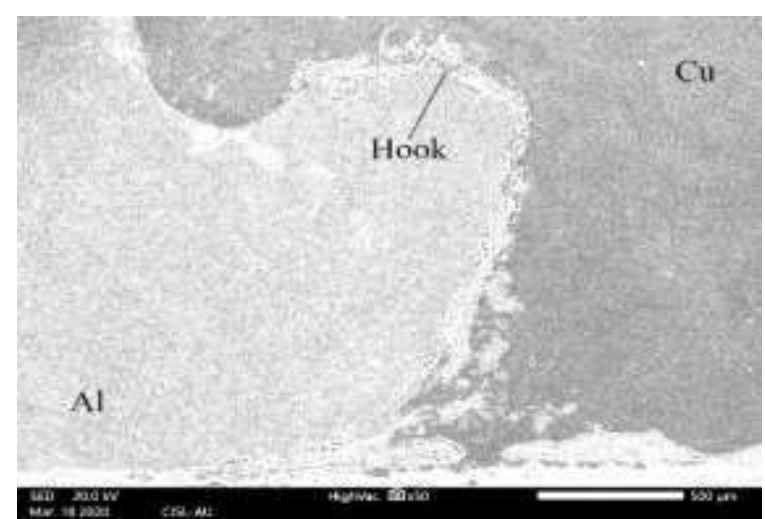

Fig 10. F (1400 rpm-Double)

\subsection{Comparative Graph Between Single and} Double Spot Welds

Table 2 illustrate the Tensile strength for the various rotational speed.

Table 2 Speed Vs Tensile Strength

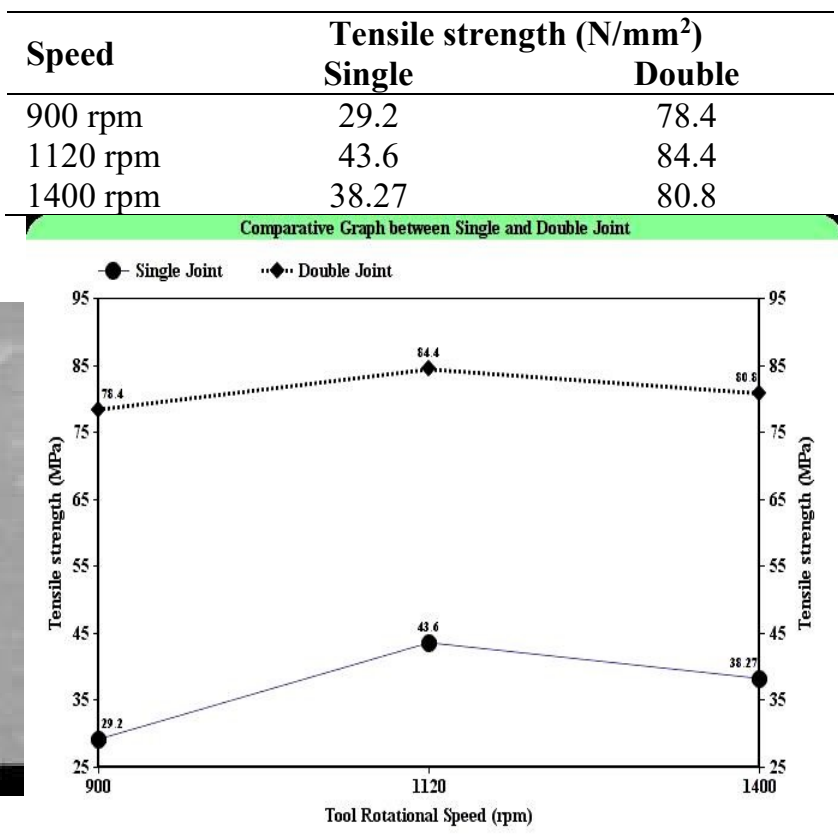

Fig. 11 Tensile strength Vs Tool Speed

Fig. 11 shows that the tensile strength and tool rotational speeds are directly proportional to each other. However, we see that the strength is maximum at a tool rotational speed of $1120 \mathrm{rpm}$. 


\section{Conclusions}

The inferences of the microstructure analysis of $\mathrm{Cu}$ and $\mathrm{Al}$ bimetallic lap joint using Friction Stir Spot welding process with the help of Transverse Tensile testing, Scanning Electron Microscopy and Energy Dispersive spectroscopy are presented below.

i. Increase in tool rotation speed will increase in mechanical strength and high transverse tensile strength.

ii. Increase in a number of welds will give more mechanical interlocking and also more tensile strength.

iii. The optimum distance between the two consecutive welds in the case of double Join can be tested and verified by conducting a greater number of experiments to fix the strength factor as future scope of work.

\section{References}

1. Thomas WM, Dolby RE (2002). Friction stirs welding developments. Proceedings of $6^{\text {th }}$ international trends in welding research conference. 203-11.

2. Akshansh Mishra et al. (2018), Friction Stir Welding of Dissimilar Metals, International Journal for Research in Applied Science \& Engineering Technology, $6(1)$

3. Balaram Yelamasetti, Hari Vemanaboina (2016) Friction Stir Welding on Dissimilar Metals Aluminium 6061 \& Pure Copper, International Journal of Scientific Research and Development. 60-

4. Kulwant Singh, Harmeet Singh, I.K.Gujral (2018), Review on Friction Stir Welding Of Magnesium Review on Friction Stir Welding Of Magnesium
Alloy, Journal of Magnesium and Alloys, 6(4):399Alloy,
5. R.Heideman (2017), Metallurgical Analysis of $\mathrm{Al} / \mathrm{Cu}$ Friction Stir Spot Welding, Science and Technology of Welding \& Joining, 15(7): 597-604

6. Mukuna Patrick Mubiayi, Esther titilayo Akinlaabi and Mamookho Makhatha (2017), Effect of Process Parameters on Tensile Strength and Morphology of Friction Stir Spot Welds of Aluminium and Copper, 8th International Conference on Mechnanical and Intelligent Manufacturing (ICMIMT)

7. Raheem $K$ et al. (2018), Friction Stir Spot Welding Applied to Weld Dissimilar Metals of AA1100 AlAlloy and C11000 Copper, IOP Conf. Series: Materials Science and Engineering

8. K.O.Sanusi (2017), Material Characterization of Dissimilar Friction Stir Spot Welded Aluminium And Copper Alloy, Conference Series Materials Science and Engineering, 225(1):012057

9. S. M.Bayazid et al. (2015), Investigation of Friction Stir Welding Parameters of 6063-7075 Aluminum Alloys by Taguchi Method, Procedia Materials Science, 11:6-11

10. Mukuna P. Mubiayi and Esther T.Akinlabi (2014), Friction Stir Spot Welding of Dissimilar Materials, Proceedings of the World Congress on Engineering and Computer Science

11. Mohamed M. Abd Elnabi, T.A.Osman (2018), Influence of Friction Stir Welding Parameters on Metallurgical and Mechnical Properties of Dissimilar Aa5454-Aa7075 Aluminium Alloys, Mechanical Design and Production Engineering Department

12. Omar S. Salih. Hengan Ou, W.Sun D.G. McCartney(2015), A Review of Friction Stir Welding of Aluminium Matrix Composites, Materials \& Design, 86:61-71.

13. S.M.Bayazid, H.Farhangi, A.Ghahramani (2015), Effect of Pin Profile on Defects of Friction Stir Welded 7075 Aluminium Alloy, Procedia Materials Science, 11:12-16 